Author's accepted manuscript of article:

Namisango, E., K. Bristowe, F. E. M. Murtagh, J. Downing, R. A. Powell, M. Abas, L. Lohfeld, Z. Ali, M. Atieno, D. Haufiku, S. Guma, E. B. K. Luyirika, F. N. Mwangi-Powell, I. J. Higginson \& R. Harding (2020) Towards person-centred quality care for children with life-limiting and life-threatening illness: Selfreported symptoms, concerns and priority outcomes from a multi-country qualitative study. Palliative Medicine. (C) The Author(s) 2020. https://doi.org/10.1177/0269216319900137

\title{
Towards person-centered quality care for children with life-limiting and life- threatening illness: self-reported symptoms, concerns and priority outcomes from a multi-country qualitative study
}

Eve Namisango, MSc; Katherine Bristowe, PhD; Fliss E M Murtagh, PhD; Julia Downing, PhD; Richard A Powell, MSc; Melanie Abas, PhD; Lynne Lohfeld, PhD Zipporah Ali, MD; Mackuline Atieno, MA; Desiderius Haufiku, MPH; Samuel Guma, MD; Emmanuel BK Luyirika, M FAM Med; Faith N. Mwangi-Powell, PhD; Irene J Higginson, PhD; Richard Harding, PhD

*Address correspondence to: Eve Namisango

African Palliative Care Association

Plot 850 Dr Gibbons Road

Kampala Uganda and

King's College London, Cicely Saunders Institute of Palliative Care, Policy \& Rehabilitation, London, United Kingdom

eve.namisango@africanpalliativecare.org /eve.namisango@kcl.ac.uk

$+256772460536$

Katherine Bristowe

King's College London, Cicely Saunders Institute of Palliative Care, Policy \& Rehabilitation, London, United Kingdom

Katherine.bristowe@kcl.ac.uk 
Fliss EM Murtagh

King's College London, Cicely Saunders Institute of Palliative Care, Policy \& Rehabilitation, London, United Kingdom and

Wolfson Palliative Care Research Center, Hull York Medical School

fliss.murtagh@hyms.ac.uk

Julia Downing

International Children's Palliative Care Network, South Africa and

Palliative Care Unit, Makerere University, Uganda

King's College London, Cicely Saunders Institute of Palliative Care, Policy \& Rehabilitation, London, United Kingdom

julia.downing@icpen.org

Richard A Powell

MWAPO Health Development Group, Nairobi, Kenya

richard2powell@yahoo.co.uk

Melanie Abas

King's College London, Health Services and Population Research Department, Institute of Psychiatry, Psychology and Neuroscience, London, United Kingdom

melanie.abas@kcl.ac.uk

Lynne Lohfeld

Queen's University Belfast, Centre for Public Health, Belfast U.K.

l.lohfeld@qub.ac.uk

Zipporah Ali

Kenya Hospice and Palliative Care Association, Nairobi, Kenya 
Desiderius Haufiku

University of Namibia, School of Public Health, University of Namibia, Windhoek, Namibia dessy@iway.na

Mackuline Atieno

African Palliative Care Association, Kampala, Uganda

mackuline.atieno@africanpalliativecare.org

Samuel Guma

Kawempe Home Care

sguma08@gmail.com

Faith N Mwangi-Powell

MWAPO Health Development Group, Nairobi, Kenya

mwangi1powell@yahoo.co.uk

Emmanuel BK Luyirika

African Palliative Care Association, Kampala, Uganda

emmanuel.luyirika@africanpalliativecare.org

Irene J Higginson

King's College London, Cicely Saunders Institute of Palliative Care, Policy \& Rehabilitation,

London, United Kingdom

irene.higginson@kcl.ac.uk

Richard Harding 
King's College London, Cicely Saunders Institute of Palliative Care, Policy \& Rehabilitation, London, United Kingdom

richard.harding@kcl.ac.uk 


\section{Abstract}

Background: Paediatric life-limiting and life-threatening conditionslife-limiting conditions place significant strain on children, families and health systems. Given high service use among this population, it is essential that care addresses their main symptoms and concerns.

Aim: This study aimed to identify the symptoms, concerns, and other outcomes that matter to children with life-limiting conditions and their families in sub-Saharan Africa.

Setting and participants: Cross-sectional qualitative study in Kenya, Namibia, South Africa and Uganda. Children/caregivers of children aged 0-17 years with life-limiting conditions were purposively sampled by age, sex, and diagnosis. Children aged 7 and above self-reported; caregiver proxies reported for children below 7 and those aged 7 and above unable to self-report.

Results: 120 interviews were conducted with children with life-limiting conditions ( $n=61$ age range 7-17 years), and where self-report was not possible caregivers $(n=59)$ of children (age range 0-17). Conditions included advanced HIV (22\%), cancer (19\%), heart disease $(16 \%)$ endocrine, blood and immune disorders (13\%), neurological conditions $(12 \%)$, sickle cell anaemia (10\%) and renal disease (8\%). Outcomes identified included: physical concerns - pain and symptom distress; psycho-social concerns - family and social relationships, ability to engage with age-appropriate activities (e.g., play, school attendance); existential concerns - worry about death, and loss of ambitions, health care quality - child- and adolescent-friendly services. Priority psycho-social concerns and health service factors varied by age.

Conclusion: This study bridges an important knowledge gap regarding symptoms, concerns and outcomes that matter to children living with life-limiting conditions and their families and informs service development and evaluation.

Keywords: Symptoms, concerns, outcomes, children, palliative care, paediatrics 


\section{Key statements:}

What is already known about the topic?

- A high number of children with life limiting and life-threatening conditions need palliative care.

- Many of these children face health related suffering with the majority living in resource limited countries.

- Evidence of symptoms, concerns and other priority outcomes for children facing life limiting and life-threatening conditions is predominantly from cancer populations, largely based on proxy reporting, and from resource-rich settings.

What this paper adds

- This study provides evidence on symptoms, concerns and outcomes that matter to children with LLC.

- Demonstrates thematic variations in symptoms, and concerns and by developmental age, that can shape support throughout an illness trajectory.

- Provides an evidence base for cross-cutting themes on symptoms, and concerns and across diverse life limiting and life-threatening conditions..

Implications for practice

- With evidence on what matters to children with life-limiting and life-threatening conditions, we can move towards the development of appropriate paediatric palliative care services, as well as developing or adapting person-centred paediatric palliative care outcome measures.

- Using developmental and age appropriate research methods, children can and should be engaged in research that shapes their care. 
Introduction

The recent Lancet Commission highlighted the individual, family and health system burden of life-limiting conditions and the "abyss" of pain and palliative care access in lowand middle-income countries (LMIC). ${ }^{1}$

In 2017 an estimated 21 million children globally needed palliative care ${ }^{2}$, with over 5.3 million facing health related-suffering; $99.9 \%$ of these live in resource-limited settings ${ }^{1}$. Despite the commitment to scale up access to paediatric palliative care as a universal human right, service development and access remain poor. ${ }^{3,4}$ While substantial evidence exists that palliative care reduces costs ${ }^{5}$ and improves outcomes in adults, ${ }^{5,} 6$ the evidence for effectiveness in children is limited ${ }^{7}$ partly due to the lack of valid child-centred outcome measures. $^{8-10}$ To generate evidence of improved treatment, outcomes and care satisfaction ${ }^{11,12}$, it is essential to first determine what matters to children with LLCs and their caregivers. ${ }^{13,14}$

To date, paediatric health care outcome measures lack palliative care relevant content validity..$^{15-17}$ Specific challenges of outcome measurement in this population include difficulties in developing tools for children with life limiting and life-threatening conditions , including variable cognitive development, impacts of advanced disease and communication impairment. ${ }^{18}$ Recent evidence on outcomes specific to this population found it largely drawn from studies of oncology patients in high-income countries using proxy (family and professional) views and expert opinion. ${ }^{8,} 19$ More so, the evidence does not consider social and developmental ${ }^{20}$ outcomes for children with life limiting and lifethreatening conditions. A recent systematic review to identify and compare definitions of indicators used to assess the impact of specialised paediatric palliative care, reported limited participation of children in the interviews because of advanced disease. ${ }^{21}$ Another review of instruments used to assess the impact of paediatric palliative care interventions equally noted the limited involvement of children in the reported data and the paucity of data on psychometric properties used to assess the impact of paediatric palliative care interventions. ${ }^{22}$

Consequently, ann evidence-based, child- and family-centred conceptual framework of priority symptoms and concerns is needed to inform service development, adaptation and development of outcome measures, as well as ensuring child participation in care and treatment decisions to align care to their priorities. ${ }^{23}$ The field cannot advance if this evidence gap is not addressed ${ }^{24}$. This study aimed to identify the most important symptoms, concerns, and outcomes for children with LLCs and their families. We define 
an outcome as change in health status or quality of life, usually resulting from a treatment or service. ${ }^{25}$

\section{Methods}

Study design and methodology: This interpretive, qualitative study adheres to COREQ reporting guidelines. ${ }^{26} \mathrm{EN}, \mathrm{MA}, \mathrm{LF}$ and $\mathrm{DH}$ (senior researchers and palliative care professionals, female [ $\mathrm{n}=3]$, and male $[\mathrm{n}=1]$ conducted in-depth interviews with children or their proxy caregivers (when children were unable to self-report; because of advanced disease as defined by the phase of illness ratings ${ }^{27}$ (end of life) or cognitive impairments as confirmed by their caregivers and nurse where appropriate), enabling the exploration and interpretation of gaps in theoretical and clinical knowledge. ${ }^{28}$

Countries and study sites: We recruited participants from in-patient and out-patient clinics across 10 tertiary hospitals and hospices in Kenya, Namibia, South Africa and Uganda.

Inclusion criteria: children aged between 0-17 years, with a LLC diagnosis and receiving palliative care. Children old enough to self-report (aged 7 years and above) were eligible to participate if they were aware of their diagnosis, had enough cognitive ability to complete an interview (according to their lead nurse), could communicate in any of the designated study languages, had received consent to participate from a parent/guardian (caregiver), and were willing to assent to participate. Caregivers of children unable to selfreport were deemed eligible if they could communicate in one of the designated study languages and give informed consent.

Exclusion criteria: child or caregiver too distressed to participate.

Sampling: We purposively sampled participants by age, sex, diagnosis, and place of care to maximize variation in the sample. These criteria were based on palliative care needs assessment evidence from South Africa. ${ }^{29}$ Appraisal of our initial data collection (2016) identified a failure to achieve a heterogeneous purposive sample, with under-recruitment of non-malignant conditions, children below the age of 5 , and those receiving care in an inpatient setting. Therefore, further recruitment was undertaken in 2017 to ensure the purposive sampling criteria were fulfilled. Recruitment ceased when thematic data saturation regarding the study aim was achieved. ${ }^{30}$

Data collection tools: We developed semi-structured topic guides, based on a review of the literature and consultation with experts. The topic guide addressed the experience of illness in the context of the child's developmental stage and living situation. ${ }^{20} \mathrm{We}$ developed two proxy topic guides for caregivers of pre-verbal or non-verbal children (0-5 
years) and caregivers of older non-verbal children (6-17 years old). Three topic guides were developed for children who were able to self-report aged 7-9, 10-14 and 15-17. The guides covered the following aspects; symptoms and concerns in living with LLCs and how these affected patients' wellbeing; overall illness and treatment experiences and its associated challenges. Concerns about how the breaking of 'bad news' (diagnosis) affected patients and families; the meaning of the illness to the patients; coping with concerns and problems; and current priorities in life were discussed with children/caregivers of children aged 7 years and above. The topic guides were forward and backward translated into local languages: Luganda, Lusoga, and Swahili (Uganda); Luo and Swahili (Kenya); Oshiwambo (Namibia); and Zulu, Sesotho and Pedi (South Africa). Each guide was pilot tested with two caregivers/children in three countries and minor revisions made.

Recruitment and data collection: At each site, the study team screened and recruited children and caregivers. Study participants were given an opportunity to ask questions and seek clarification. For each interview, we obtained informed consent from carergivers.Self-reporting children assented in addition to the consent from their carergivers. After informed consent and/or assent, interviews were conducted in private rooms, children were interviewed without their caregivers. Each interviewer completed a 2-day training course delivered by the principal investigator (EN) and two child psychologists. Interviews began with a brief period of play and storytelling (appropriate to developmental age) to build rapport. ${ }^{31}$ Children were encouraged to talk freely, share their views, experiences, and issues that matter to them. ${ }^{32}$ For interviews with younger children of up to 10 years, a play interlude of 15 minutes was given. A social worker was available at each study site to support participants if they became distressed. All participants were informed about this and about their freedom to choose who should support them and that they could decline to answer questions or stop the interview at any time. No repeat interviews were conducted.

Ethics: Formal ethical approval was granted in all participating countries: Kenya (refs: $\mathrm{KEMRI} / \mathrm{RES} / 7 / 3 / 1$ and ERC/B/VOL1374), Namibia (ref: 17/3/3/EN), South Africa (ref: HPCA 03/10) and Uganda (ref: UNCST SS2366) and King's College London, Research Ethics Office (LRS-15/16-3524). Written informed consent was obtained from caregivers for their children to participate in the study. Additionally, written assent was obtained from self-reporting children aged 7-17 years following approval to participate in the study from their caregivers. All children received an age-appropriate gift worth USD7 given at the end to acknowledge participation but was not mentioned in any study materials and refreshments during the interviews. 
Data processing and analysis: The study team digitally audio-recorded interviews, alongside field note taking and transcribed them verbatim, pseudonymised, and imported into QSR NVivo V12. Interviews conducted in local languages were translated into English and reviewed by local bilingual study partners for accuracy. We analysed data using the six linked steps of inductive thematic analysis (see Table 1) to identify themes symptoms, concerns, and other outcomes. Our study is underpinned by the Bronfenbrenner's bio-ecological Systems theory, adapted for palliative care. ${ }^{33}$ It highlights the micro, meso, exo, macro and chrono systems of the socio-ecological layers. With increasing developmental age, the child's level of interaction at socioecological layer level expand. The Chronosystem is concerned with the concept of changing needs by developmental age, disease stage, and function, as well as interconnectedness across layers. (see supplementary material 1) We compared theme variation by developmental age: $0-2,3-5,6-9,10-14,15-17 .{ }^{34}$

For data presentation, the definition of theme categories was guided by outcomes literature in paediatric palliative care, ${ }^{35} \mathrm{Himelstein's} \mathrm{framework} \mathrm{for} \mathrm{delivering} \mathrm{paediatric}$ palliative care, ${ }^{36}$ and the $\mathrm{WHO}$ definition for paediatric palliative care ${ }^{37}$, framework for palliative care outcomes and the International classification of function, disability and health. ${ }^{38}$

[ insert Table1]

Rigor: To ensure data credibility, the research team provided the breadth of necessary experience: Paediatric palliative care, nursing, child health and psychology, qualitative methods, psychometrics, and medical anthropology. To enhance transferability, rich description of the research process, setting and participants is included.To ensure dependability and confirmability, dual-coding, and careful study record-keeping was undertaken. ${ }^{39}$

\section{Results}

\section{Sample characteristics}

We conducted 120 interviews with 61 children (95\% of those approached) and 59 family caregivers (100\% of those approached). Child participants ranged from 1 day to 17 years old; $52 \%$ were female, and $81 \%$ had a non-malignant condition (Table 2). Child interviews lasted a median of 37 minutes (range 35-50 minutes), with older children participating in longer interviews. The reported excludes the play interlude. Caregiver interviews lasted a median of 55 minutes (range 50-60 minutes). The majority of proxy reporting caregivers were mothers $(n=38,64.4 \%)$. 
[Insert Table 2]

Symptoms and concerns

Four main thematic concerns emerged from the data: physical concerns, existential/spiritual concerns, psychosocial issues, and concerns regarding health care quality. (Figure 1). These are described below with illustrative quotes (see supplementary material 2 for additional quotes to support the themes) alongside following attributes; type of respondent, age of child and country setting code.

[Insert Figure1]

(i) Physical concerns

Commonly described symptoms included: pain; fatigue; difficulty walking or moving; skin problems (rash, change in skin texture); gastro-intestinal problems (nausea, vomiting, diarrhoea); respiratory problems (breathlessness, cough, fast breathing) ;(quotes 1-2) and central nervous system symptoms (seizures and convulsions).

When my body swells, it causes me severe pain, my legs are heavy, and I cannot move, and my stomach is also too heavy. Somehow, I cannot sleep well, and my wellbeing is negatively affected. I just want the water to be removed and I get some relief. Also, the skin darkens, I get funny patches on the skin and the outer layer is very tight. Child 44 -age-group 10-14 years -KE-[ quote1]

The child starts with swollen feet, vomiting, tired, cannot breathe well, and stomach pain. Caregiver -01 -child's age-group 6-9 years -NA-[quote 2]

These symptoms, particularly pain, were associated with distress. Children reported experiencing an excruciating pain not easily explained, using terms like "throbbing", "constant" "painful insect bite" (quotes 3). Children as young as ten expressed the desire to die to escape the pain (quote 1), while those with sickle cell disease described a life of constant uncertainty and fear of the unpredictable pain episodes (quote 4). Symptom distress was also expressed in relation to the impact on wellbeing, function, and activities of daily living. 
When the pain starts. I just feel like dying, I just admire death, I yearn for an injection to kill me off because the pain is so severe. I just yearn for death to free me from pain, it is not even equitable to the most painful insect bite, its gnawing you just want to die and be free from the pain. Child 41-age-group 15-17 yearsUG-[qoute3-]

I hate it because the pain comes abruptly, it can find you in the middle of town and you collapse. sometimes the pain starts from the back. It is throbbing and very severe. Sometimes it is the joints that pain or ankles, at this point you lose the capacity to walk or stand, you can crawl may be, but you need support. Sometimes the chest gets so painful other times it is the arms, It's all about pain. Child 29child's age-group 10-14 years-KE-[quote4]

Caregivers frequently described using the presence of concerns, such as not feeding (especially in infants and non-verbal children), as a measure of their child's health status and well-being. Difficulty in feeding was a sign for an underlying serious problem (quote $5)$.

The jaws are terribly weak and so he has not been sucking and as a result he has malnutrition. Caregiver 18- child's age-group 0-2 years- UG-[quote5]

Children expressed the importance of being able to maintain physical function in activities, such as self-care and play (quote6). Caregivers expressed similar concerns, with dependence on others often regarded as the most difficult challenge for their children (quote7)

The swelling of the body, especially the eyes and body, it comes with severe pain, when I stop the medication, the pain crops back so I must be on medication all the time and I just hate. I cannot lift a jerry can, I cannot wash or even run. Child 48age-group 10-14 years- UG [quote 6]

The hardest thing about my child being sick is his dependency to other people, this is so because of mental retardation. Carergiver-50-child's age-group 15-17 years _UG- [quote 7

(ii) Existential/spiritual concerns 
Existential/spiritual concerns were evident across all age groups. Children were worried about death, transitioning to an afterlife, and letting go of their loved ones. The children were also worried about losing their future dreams and missing out on schooling, whilst other expressed hopelessness and a reluctance to continue with their education, take their medication or think of their future life. (quote 8)

You are concerned, you will lose your education. Sometimes you lose morale for education and feel like drop in out. When I think of starting up a business, I also lose morale because I am constantly thinking about the death. So, life gets crippled you cannot move forward. Child-10-age-group 10-14 years-UG-[quote 8]

Caregivers equally voiced concerns of lost dreams, regarding issues that matter to their children quote 9 ).

He is not aspiring to something big in life because he is mentally challenged.

Caregiver-59-child's age-group 15-17 years - NA [quote 9]

Children reported being concerned by unanswered existential questions, including 'Why me?', questioning why it had to be them to suffer adversity when their siblings were healthy. All this compounded the challenges children faced around unanswered questions (quote 10).

I always wonder why God brought this painful disease to me. At my church, we are told God loves children but now Imagine what I am going through. I always ask myself why me, and I have never found the answer, so I have given up on asking. I just keep it to myself. Child-42-age-group -6-9 years -KE-[quote 10]

Children who felt connected to a supernatural being expressed a more positive attitude towards suffering, accepting their illness as God's will safe in the knowledge that God would support them through their illness (quote 11).

What is most important to me is God, my mother and my father. God is very important in my life because we pray to him so that we can live in this world, he created us. He also has all the authority to decide if one lives or dies. Child-3 agegroup 10-14 years $-N A-[$ quote 11]

In some instances, caregivers noted that children expressed a belief that they had undergone spiritual growth because of their suffering. Their life was perceived as a gift, and their suffering was embraced as part of their life (quote 12). 
She just wants to cure completely and resume living a normal life. She asks me when she will get well and go for boxing. She also tells me "Now I appreciate that walking is a big gift from God, I can never take it for granted again". Carergiver-13 -child's age-group 6-9 years -UG-[quote 12]

According to caregivers' reports, children as young as five years were concerned about dying with unfulfilled dreams (quotes 13). More so, uncertain prognosis was associated with meaninglessness for children.

She [the child] is worried about dying young. She has not even completed her education, so she is worried. She hates going to the theatre she always tells me that there are two possible outcomes, get better or die in the process but she always notes that God is in control. Caregiver child's age-group 3-5 years -UG[quote 13]

Some caregivers associated severe crying of neonates with suffering due to family rejection (children born with life limiting and life-threatening conditions are sometimes rejected by their families and are not given names, resultantly, lack family tree belonging (quote 14).

Then he [the child] also very annoyed because he [the child] does not have a name yet, when the father heard about this problem, he switched off the phone he thinks this is a curse to the family. So, my son is crying, he wants to belong to family and this not falling into place, so I have a very serious problem. Caregiver-12- child's age-group 0-2 years$K E$-[ quote 14]

Caregivers of pre-verbal children recognised calmness as an important indicator of the spiritual well-being of their children (quotes 15)

The situation in which he is now shows that he is at peace he no-longer cries at all. Carergiver-33- child's age-group-3-5 years_UG-[quote 15]

(iii) Psycho-social concerns

Children described in depth the psycho-social aspects of the illness experience. They described negative emotional responses, including sadness, anger, mood swings, and suicidal ideation (quote 16). 
I have had to accept my situation. I am angry. I feel like it's a punishment and I need to get over it. I keep asking Why me? I was also depressed and cried a lot. I tried to commit suicide; I thought there was no point as my CD4 was low. Child 06- age-group 15-17 years -SA-[quote 16]

In addition, caregivers and children described the importance of fun, happiness and living in the moment. They also wished to engage in activities that gave them fun and meaning (quote 17-18).

She also tells me to take her back to school, she keeps referring to other children who are attending school and asks me to take her back to school. She is bed bound and is so sad because she cannot play. I thank God that she is able to laugh and ask for what she wants. Caregiver 23 child's age group 6-9-KE.[quote 17]

This year I was going in P5 but due this sickness i wasn't able to go to school I am now here. So, I miss all my friends at school, and I may never see some of them again. I also lose out on being in school, I want to be a mechanic. I am sick but I am happy because I play with my colleagues here, we don't fight. When I play well with my colleagues, when the health workers play with us, it makes me very happy. Child 20 age group 10-14- UG[quote 18]

There were also treatment/medicine related concerns such as; pill burden, taste of medication and medication fatigue, all of which contributed to non-adherence (quotes 19).

I really want the experts to come up with a cure, I have lived with this disease for long, but I am still dreaming about the cure ((laughs)). If those doctors can reduce on the number of tablets I take in a day, it's too much you cannot live like this forever. Child 28-age-group 10-14 years -UG - [quote19]

The caregivers also described concerns related to treatment poor treatment adherence , which was associated with worry about child survival. Other concerns included behavior that put children in conflict with family members. (quote 20).

I am worried that [name] is not taking medications, I am afraid she will die. She is also cheeky and causing family problems and conflict. Caregiver 18_ child's age group 15-17 years-SA-[quote 20]

Caregivers, also highlighted behavioural concerns exhibited by the children such as negative emotions, particularly suicidal ideation, and loss of interest in previously enjoyed activities (quote 21).

Anger, she does not understand why she has HIV. She is also depressed and tried committing suicide this year, by hanging herself. caregiver-53- child's agegroup 15-17-SA - [quote21] 
Caregivers also noted cognitive or developmental concerns related to the onset of the life limiting and life-threatening conditions were cited (quote 22).

I think her reasoning is declining, she not as intelligent as she used to be, she cannot add simple number. For me I am very worried, could be doctors are not telling us the truth about what happened to her. She is very quiet I do not know why; no single sound is coming out. Caregiver21- child's age-group 3-5 years $K E$ - [quote 22]

For adolescents, much of the focus was on body image and wasting (quote 23).

My biggest concern is the fact my body swells, and I just look so bad. It affects my image, my legs and face the most beautiful parts of my body so why they swell and lose the beauty I feel so bad. Child-25- child's age-group 15-17 years-UG- [ quote 23]

Children and caregivers attached high importance to normalcy, being able to achieve ageappropriate developmental milestones, including such simple outcomes as crying or feeding, and being treated like unaffected peers (quotes 24-25).

He cannot kick his legs around like normal children, he cannot even move his body at all, he breastfeeds well and passes urine like a normal child but there are those problems. Caregiver 12-child's age-group 0-2 years_KE-[quote 24]

I want to have life, I want to live up to the age of 25, get married and have a child, just like other children. That is the most important thing in my life. Child 21 agegroup 15- 17 years - UG [ quote 25]

School-going children were concerned about missing school, and the negative impact of interruptions impacted on the quality of social interactions, relationships, and life goals (quote26). Children wanted time to interact with peers, feel understood, listened to, respected and appreciated.

This year I was meant to join primary 5, but due this sickness I couldn't go to school I am now here. So, I miss all my friends at school, and I may never see some of them again. I also lose out on being in school. When I play well with my colleagues, when the health workers play with us, it makes me very happy. Child 39-child's age-group 6-9 years-_KE-[quote 26] 
More so, according to caregivers of the non-verbal children, spending less time with significant others impacted on the quality of social relationships (quote 27).

He recognises me we are enjoying our small world. As soon as I sit on the bed he stops crying. He is calm and quiet. Caregiver 06- child's age-group 0-2 years $-U G$ [quote 27]

Regarding family relationships, children highlighted the importance of having a positive family environment as part of their social support structure. They valued love, physical presence and quality time with their significant others (quote 28).

Despite all this, what I like about it all is that I am very special to my mother am very close to her all so that is a good thing on my side. Child 2- child's age-group 6-9 years $-K E$ - [quote 28]

Genetic illnesses such as sickle cell commonly strained family relations and at times led to separations. This happened on two levels; children were treated like outcasts as male partners posited that their family trees could not be associated with such illnesses. Some children also questioned their lineage as these illnesses seemed to affect them alone and their siblings were healthy (quote 29).

The men always blame the women. Yet this is a genetic problem which could be on the man's side. So, my mother was thrown out of the home and we are struggling. Men believe all the bad things are brought in by the women. This should stop. I want to know why I have this disease and why is it me of all the children. it is only me with this disease, we are five children and I am the last born. Why is it me only, why isn't it at least two or three people in the family? I want an answer. Child 16-child's age-group 15- 17 years-NA [quote 29]

Children also worried about protecting their families from any bad experiences. For example, one child explained why she would withhold news about her worrying symptoms because she was concerned that it would cause distress to her family (quote 30) 
When I fail to breathe, I just keep quiet. I do not want to worry other people; some people are already ill so if you share such bad news they can collapse into comma and die. So, for me I just rely on God he decides if you one must die or survive. Child 34, age group - 10-14 years-KE -[quote 30]

Caregivers of pre-verbal children reported cases of pyscho-social distress linked to lack of a "name" which connected the children to a family tree and gave them a sense of belonging (quotes 31 ).

Then he also very annoyed because he does not have a name yet, when the father heard about this problem, he switched off the phone he thinks this is a curse to the family. So, my son is crying, he wants to belong to family and this not falling into place, so I have a very serious problem. Caregiver-12- child's age-group 0-2 years $-K E$ - [quote 31]

Some children reported being given names associated with the suffering of living with LLC; for some of them this was a source of value and strength (quote 32).

When am ill I always ask my mother, why is it me who got this disease and she tells me she does not know? It is just that. So, I think it was God's decision, God decided that of all people in my home it should be me to live this way. That is why I was given this name [name] just to say it is God who decided. I am like this because it is God's choice. In fact, the full name is [name translated as [name] what God decides]. I had another name [name] but I prefer to use the latter, am what I am because it was God's choice. In fact, I was given this name when my parents first learnt of my diagnosis. Child 57, age group 15-17 years. [quote 32]

Caregivers were concerned about their children having to deal with stigma and bullying due to looking different from others, such as when facing severe weight loss, or peers knowing about their diagnosis (quote 33)

My brothers' physical appearance, is he going to stay small forever, will he ever grow. He is bullied and teased at school, because he is small for his age. Caregiver-31 -child's age-group 15-17 years-SA [ quote 33]

Children also noted negative stereotypes about children living with LLC. This negatively impacted on their self-esteem and personal identity. Negative body image and fears of stigma, discrimination and rejection also impacted on adolescents wishing to initiate sexual relationships (quote 34 ) 
There are several people who laugh at [me], I got a woman she had a child and died. So, my family members started saying you see, a "sickle" should not engage in sex, they should not have children or even have relationships. Even now I have a girlfriend, but I am very cautious, am hesitant to go and have sex with her, I still live with my father. I am very worried I could die during sex, so I just try to avoid it. It is shameful if you die during this act. Child9-child's age-group 15-17 years_KE[ quote 34]

Lastly, caregivers described the catastrophic financial expenditures associated with care and struggles to balance the need to work and earn money, and to care for terminally ill children and their siblings. Some adolescents had taken on the onus of meeting their own transport-related costs and increasingly found it difficult to meet such demands (quotes 35-36). Participants also described the need for practical support to meet the physical need of food.

Financial problems. I live far away from the hospital and living off grants.

Transport is expensive. I need more financial support. Caregiver 04- child's agegroup 6-9- years -NA- [ quote 35]

As I told you earlier on that at home, we are not financially okay so sometimes I would fail to get money for transport to take me to [name of health facility] and get my treatment so I would miss. But even if I explained to them, they could not listen much as I told them the truth. They took me to the counsellor and the counsellor told me that they were going to write me off their program. Child 26-17 years -UG[quote 36]

Caregivers of children with mobility problems mentioned need for support with wheelchairs to ease the mobility of their children (quote 38)

He is not able to turn himself, if you leave him in a certain position, you will find him in that position no matter how far you went so the condition affect his body movement, he always need someone to turn him, bath and feed. I was sent to a hospital-based self-help project to buy a wheel chair using my own money. Caregiver 03 -child's age-group10-14- years -NA - [ quote 38]

(v) Health care quality 
Children felt it critical to have a positive and friendly working relationship with health service providers due to their need for chronic care until death. Those who reported friendly and supportive staff attitudes felt happy to remain in care and adhere to clinical treatment; those reporting negative staff interactions wanted to disengage (quote 39)

That day they abused her [mother to the child] and she came back home upset, so when I went back for the next visit, I asked them why they abused my mother since that time they became ruder to me. And they told me that for us we have never abused your mother, however the health workers try to empower parents show more responsibility to their children. But I felt so bad, when they abused my mother. Even tomorrow is my treatment day and I must go there but I have fears of what will happen to me, I don't know what they are going to tell me this time. Child 44- child's age-group 15-17 years-KE- [quote 39]

Caregivers of hospitalized verbal children described the difficulties of sharing wards with adult patients (participants reported this situation as a problem in Uganda's disease specialty wards alone), including emotional distress from adult conversations and at times their poor mental health (quote 40)

She doesn't want to be here. She sees adult patients stripping naked and she tells me "mama look at this patient, look the other patient his body...". All this [these] impact on her psychological wellbeing. These are people with neuro problems and some of them have lost their orientation. Caregiver 13 -child's agegroup 6-9 years -UG- [ quote 40]

Children were also concerned about sharing wards with adults, they expressed preference for designated paediatric wards and were concerned about seeing deaths of their friends which was triggered mental distress (quote 41)

Well, being with these old people here is not good at all, I want to with children when hospitalized. I also wonder, my friend died, I am hurt, so how many days do I have left to live? Child 15, child's age group 10-14 years -UG [quote 41]

According to caregivers' reports, the high patient mortality rate also caused panic and anxiety; sometimes, children worried their death would also be painful or bad (quote 42). 
She tells me I want to go home because she is not used to this environment it is strange. My daughter told me she was so worried about death because most the people on the ward were dying. The mortality rate is very high on this ward, so she is always worried she might be dying next. She wants to play her siblings those are not here. Caregiver 16_child's age-group 10-14 age 14 years-UG - [ quote 42]

Caregivers reported that their children need information about their illness and treatment to help them make sense of what was happening to them (quote 43)

The other thing is lack of information; my daughter wants to find out what the CT scan results mean but the health workers just speak their English and walk off. ...she is worried that maggots could be breeding inside her head, the pus is just too much. Caregiver 19- child's age-group 6-9 -UG- [ quote 43]

Older children and adolescents described concerns related to a lack of information, disclosure of diagnosis and being left out of conversations related to their care. Some children had not been told about their diagnosis and discovered informally, such as by eavesdropping. They interpreted this as family betrayal, and it invoked bitter sentiments (quotes 44). Adolescent children were also concerned about not having platforms for getting their questions across to health workers (quote 45). Some of them also felt there was no safe space to ask the questions that matter given there were much younger children present.

They intimidate us, you are a young girl and the doctor is much older and superior laughter, they also show us that they are very busy. So somehow there is no opportunity for us to ask any questions. We have a television here I wish they could bring us some educative tapes and we learn on our own. Child 36- child's agegroup 15-17 years -UG - [ quote 44]

Even now I have a girlfriend, but I am very cautious, am hesitant to go and have sex with her, I still live with my father. I am very worried I could die during sex, so I just try to avoid it. It is shameful if you die during this act. No, there is no privacy around here, so I do not have an opportunity. There are younger children, so you cannot ask such questions. Child 09 age group 15-17 years - UG [quote 45]

Theme variation by developmental age

We also conducted a stratified analysis by developmental age, and the findings by theme variation are presented in Table 3. The themes on pain and other symptoms, physical function, indicators of spiritual wellbeing, connection to creator, positive and negative emotions, quality of social relationships, stigma and discrimination were overarching across all developmental age groups. Normalcy, outlook on self, spiritual growth, existential loss and worry, severe pain, was mentioned by children or caregivers of 
children aged (6 years and above). Severe pain triggering search for escape were dominant themes for self-reporting older children (7 years and above).

[Insert Table 3]

\section{Discussion}

This study describes the domains of health-related suffering faced by children living with LLCs and their families. Emergent themes included symptoms and concerns in children living with LLC and their families in the domains of physical, existential/spiritual, and psychosocial concerns, and health care quality. While this supports the WHO statement that difficulties affecting adults with LLCs are relevant for children ${ }^{37}$, this study describes the additional and unique concerns related to activities of daily living (such as play, life goals and values, going to school, "name" happiness, biological growth, and development that matter to children and caregivers.

Children described the psychosocial impact of LLCs specifically in relation to their ability to engage in their usual activities, such as playing, having fun, attending school and achieving their dreams when they become adults. ${ }^{40}$ They described concerns about normalcy and maintaining their 'child identity', and the shame, anger, and stigma of not being able to do what their peers can do, which in turn led to discrimination and reluctance to access services. The singular theme of "name" was a unique finding. In the African culture, personal names may have meanings, may affect one's personality and affect their ability to thrive in society. ${ }^{41}$ This may be because the lack of a "name" is associated with lack cultural identity and pride, which are critical ingredients for ability to thrive and hence worth addressing in paediatric palliative care.

In addition, the children also described distress related to future unfulfilled dreams and concerns about death and the afterlife. The prominence of the psychosocial and spiritual concerns described by even very young children was surprising but highlights the need to address these concerns to improve child wellbeing, self-efficacy, resilience, coping and retention in care. ${ }^{18,42-44}$

The experience of symptoms also differed by age for children and their caregivers. For many children, pain was associated with fear, but for young children pain was associated with fear of impending death, whilst for adolescents it mediated desires for death to escape distress and suffering ${ }^{45}$. For some children, anticipated treatment and procedurerelated pain impacted most heavily on their wellbeing. ${ }^{46}$ These findings illustrate the multidimensionality of pain and its impact on the whole person (i.e., "total pain"). ${ }^{47}$ 
Children and caregivers expressed the importance of child-friendly services, drawing a link between issues such as emotional distress associated with exposure to high mortality rates on inpatient wards, unapproachable staff, and their negative impact on their wellbeing. 48,49 These findings suggest that to improve care, health care quality and the additional existential/spiritual and psycho-social concerns should be considered.

Lastly, children may not always be able to self-report, so proxy reporting is important to consider. There was considerable overlap in the concerns expressed by children and caregivers; however, while caregivers could report on visible and functional concerns, self-report is required for emotional and abstract constructs. ${ }^{50}$

\section{Strengths and limitations}

This study contributes to the evidence gap related to the problems and concerns of children with LLC ${ }^{19}$ through a large dataset, based on a comprehensive purposive sampling frame and includes: self-report by children (and caregivers where that was not possible); across diverse age and diagnostic groups; and in resource-limited settings, increasing the transferability of the findings. We also undertook stratified analysis by developmental age and generated important evidence on differences in concerns. Our study has limitations: due to recruitment difficulties and variation in access to palliative care services ${ }^{4}$, the number of participants from each country varied, with the greatest proportion of participants from Uganda (43\%) and the least from South Africa (12\%). Moreover, we interviewed children about complex constructs, which they might find challenging to elaborate upon comprehensively given their limited vocabulary. Resultantly, some details could have been missed due to inadequacies in language. However, consistent with the existing developed country-based evidence, we found multidimensional concerns which have been posited to be important in patients living with LLC, reinforcing the validity of our findings. ${ }^{19,51}$

\section{What this study adds}

This study provides evidence on symptoms and concerns that matter to children with LLC and their families within the core domains of physical, spiritual/existential, pyscho-social and quality of care. We, therefore, recommend a multi-professional approach to care with attention to quality of services, as well as the multi-dimensional child and family concerns. Our study also demonstrates the feasibility of, self-report in children and the use of ageappropriate or colloquial language, which should be a key consideration for research involving children.

These data also inform the evidence base on defining the construct of "symptoms and concerns" in paediatric palliative care which is pivotal to effective service evaluation.

These novel data address gaps in the literature by collecting primary self-report data in LMICs.

\section{Declarations}


Availability of data: The transcripts are not publicly available for confidentiality reasons, but we share anonymised verbatim quotes to support the themes generated as primary data.

Funding: This study was funded by AIDSTAR-One USAID (AIDSTAR-One-001) and the Open Society Foundation as BUILDcare African funders. The funders, AIDSTAR One and the Open Society Foundation as BUILDcare Africa, played no role in the study design, the collection, analysis, and interpretation of the data, the writing of the report or the decision to submit the paper for publication.

Authorship: Study concept and design, analysis and interpretation of the data, drafting of the manuscript, and critical revision of the manuscript for important intellectual content: Eve Namisango, Katherine Bristowe, Fliss EM Murtagh, Julia Downing, Richard A Powell, Mackuline Atieno, Richard Harding.

Analysis and interpretation of the data, drafting of the manuscript, critical revision of the manuscript for important intellectual content: Irene J Higginson, Melanie Abas, Lynne Lohfeld Emmanuel BK Luyirika, Faith N. Mwangi- Powell.

Study supervision, drafting of manuscript, administrative, technical and material support: Zipporah Ali, Desiderius Haufiku, Samuel Guma.

All authors approved the final manuscript as submitted and agree to be accountable for all aspects of the work.

Declaration of conflicts of interest: All authors declare that they have no financial relationships or personal relationships with other people or organisations that could inappropriately influence this work.

\section{Acknowledgments}

The authors are grateful to the children and caregivers who participated in the interviews and the management of the following hospitals and hospices for granting permission to recruit study participants from their facilities: in Uganda - Mulago Teaching and National Referral Hospital (renal, neuro and sicklecell clinics), the Uganda Heart Institute; Hospice Africa Uganda, Mildmay Uganda, and Kawempe Home Care; in South Africa the Red Cross Children's Hospital; in Kenya, Kisumu and Nyahururu Hospices, and New Nyanza Provincial Hospital (currently Jaramogi Oginga Odinga Teaching and Referral Hospital); and in Namibia, Oshakati Hospital. We are also grateful to the nurses who coordinated patient recruitment and the child psychologists that trained our interviewers. We also 
thank Ivy Kasirye, Jenny Ssengooba and Michelle Meiring who supported study participant recruitment. 


\section{References}

1. Knaul FM, Farmer PE, Krakauer EL, et al. Alleviating the access abyss in palliative care and pain relief-an imperative of universal health coverage: the Lancet Commission report. Lancet 2018; 391: 1391-1454. 2017/10/17. DOI: 10.1016/s0140-6736(17)32513-8.

2. Connor S, Downing $\mathrm{J}$ and Marston J. Estimating the Global Need for Palliative Care for Children: A Cross-sectional Analysis. J Pain Symptom Manage 2017; 53: 171-177. 2016/10/22. DOI: 10.1016/j.jpainsymman.2016.08.020.

3. Knapp C, Woodworth L, Wright M, et al. Pediatric palliative care provision around the world: a systematic review. Pediatric Blood \& Cancer 2011; 57: 361-368.

4. Rhee JY, Luyirika E, Namisango E, Powell RA, Garralda E, José Pons J, de Lima L, Centeno, C. APCA Atlas of Palliative Care in Africa. IAHPC Press; 2017, 2017.

5. Gomes B, Calanzani N, Curiale V, et al. Effectiveness and cost-effectiveness of home palliative care services for adults with advanced illness and their caregivers. Cochrane Database Syst Rev 2013; 6. Meta-Analysis

Research Support, Non-U S Gov't

Review.

6. Temel JS, Greer JA, El-Jawahri A, et al. Effects of Early Integrated Palliative Care in Patients With Lung and GI Cancer: A Randomized Clinical Trial. J Clin Oncol 2017; 35: 834841. 2016/12/29. DOI: 10.1200/jco.2016.70.5046.

7. Chong PH, De Castro Molina JA, Teo K, et al. Paediatric palliative care improves patient outcomes and reduces healthcare costs: evaluation of a home-based program. BMC palliative care 2018; 17: 11-11. DOI: 10.1186/s12904-017-0267-z.

8. Harding R, Sherr, L., Gwyther,L. Pediatric palliative care in sub-saharan Africa: a systematic review of the evidence for care models, interventions, and outcomes. J Pain Symptom Manage 2014 47: 642-651.

9. Coombes LH, Wiseman T, Lucas G, et al. Health-related quality-of-life outcome measures in paediatric palliative care: A systematic review of psychometric properties and feasibility of use. Palliat Med 2016; 31: 0269216316649155.

10. Johnston EE, Rosenberg AR and Kamal AH. Pediatric-Specific End-of-Life Care Quality Measures: An Unmet Need of a Vulnerable Population. J Oncol Pract 2017; 13: e874-e880. 2017/09/16. DOI: 10.1200/jop.2017.021766.

11. Fayers. P.; Machin. D. Quality of life: the assessment, analysis and interpretation of patient-reported outcomes. 2nd ed. England John Wiley \& Sons, 2007.

12. Ekman I, Swedberg K, Taft C, et al. Person-centered care--ready for prime time. European journal of cardiovascular nursing : journal of the Working Group on Cardiovascular Nursing of the European Society of Cardiology 2011; 10: 248-251. 2011/07/19. DOI: 10.1016/j.ejcnurse.2011.06.008.

13. Hinds PS, Burghen EA, Haase JE, et al. Advances in defining, conceptualizing, and measuring quality of life in pediatric patients with cancer. Oncology Nursing Forum 2006; 33: 23-29. Review.

14. Hinds PS, Gattuso JS, Fletcher A, et al. Quality of life as conveyed by pediatric patients with cancer. Quality of Life Research 2004; 13: 761-772. DOI:

10.1023/b:qure.0000021697.43165.87.

15. Collins JJ, Byrnes ME, Dunkel IJ, et al. The measurement of symptoms in children with cancer. Journal of Pain \& Symptom Management 2000; 19: 363-377. 
16. Collins JJ, Devine TD, Dick GS, et al. The measurement of symptoms in young children with cancer: The validation of the Memorial Symptom Assessment Scale in children aged 7-12. Journal of Pain and Symptom Management 2002; 23: 10-16. DOI: 10.1016/s08853924(01)00375-x.

17. Huang IC, Shenkman EA, Madden VL, et al. Measuring quality of life in pediatric palliative care: challenges and potential solutions. Palliat Med 2010; 24: 175-182. DOI: $10.1177 / 0269216309352418$.

18. Evan E., Calonico E, Tan J, et al. A Qualitative Approach to Understanding Quality of Life in Pediatric Palliative Care. Palliative Care \& Medicine 2012; S1. DOI: 10.4172/21657386.S1-005.

19. Namisango E, Bristowe K, Allsop MJ, et al. Symptoms and Concerns Among Children and Young People with Life-Limiting and Life-Threatening Conditions: A Systematic Review Highlighting Meaningful Health Outcomes. The patient 2019; 12: 15-55. 2018/10/27. DOI: 10.1007/s40271-018-0333-5.

20. Bronfenbrenner U. The bioecological model of human development. In: U. Bronfenbrenner (ed.) Making Human Beings Human: Bioecological Perspectives on Human Development. Thousand Oaks, CA: Sage Publications, 2005.

21. Widger K, Medeiros C, Trenholm M, et al. Indicators Used to Assess the Impact of Specialized Pediatric Palliative Care: A Scoping Review. J Palliat Med 2019; 22: 199-219. 2018/12/12. DOI: 10.1089/jpm.2018.0420.

22. Friedel M, Aujoulat I, Dubois AC, et al. Instruments to Measure Outcomes in Pediatric Palliative Care: A Systematic Review. Pediatrics 2019; 143 2018/12/12. DOI:

10.1542/peds.2018-2379.

23. unicef. THE CONVENTION ON THE RIGHTS OF THE CHILD: Guiding principles: general requirements for all rights, https://www.unicef.org/crc/files/Guiding_Principles.pdf (accessed 09/02/2019 2019).

24. Harding R, Wolfe $\mathrm{J}$ and Baker JN. Outcome Measurement for Children and Young People. J Palliat Med 2017; 20: 313. 2017/01/11. DOI: 10.1089/jpm.2016.0525.

25. Higginson IJ and Harding R. Outcome measurement In: In J.M. Addington-Hall EB, I.J. Higginson and S.Payne (Eds.), (ed) Reseach Methods in Palliative Care (PP99-110). Newyork: Oxford University Press 2007.

26. Tong A, Flemming $\mathrm{K}$, Mclnnes $\mathrm{E}$, et al. Enhancing transparency in reporting the synthesis of qualitative research: ENTREQ. BMC Medical Research Methodology 2012; 12: 181. Research Support, Non-U.S. Gov't.

27. Masso M, Allingham SF, Banfield M, et al. Palliative Care Phase: inter-rater reliability and acceptability in a national study. Palliat Med 2015; 29: 22-30. 2014/09/25. DOI:

$10.1177 / 0269216314551814$.

28. Thorne S. Interpretive description. Walnut Creek: CA: Left Coast Press. , 2008.

29. Connor S, Sisimayi C, Downing J, et al. Assessment of the need for palliative care for children in South Africa. Int J Palliat Nurs 2014; 20: 130-134. 2014/03/29. DOI:

10.12968/ijpn.2014.20.3.130.

30. Charmaz K. Constructing Grounded Theory London: SAGE publications 2014.

31. Dell Clark C. In a Younger Voice: Doing Child-centered Qualitative Research. New York Oxford University Press, 2011.

32. Sloper $\mathrm{P}$ and Lightfoot J. Involving disabled and chronically ill children and young people in health service development. Child Care Health Dev 2003; 29: 15-20. 2003/01/22.

33. Pask S, Pinto C, Bristowe K, et al. A framework for complexity in palliative care: A qualitative study with patients, family carers and professionals. Palliat Med 2018; 32: 10781090. 2018/02/20. DOI: 10.1177/0269216318757622.

34. Christ G, H. Healing Children's Grief New York . Oxford Oxford Uinversity Press Inc., 2000. 
35. Anthony S, Selkirk E, Dix D, et al. Quality of life from the perspective of pediatric cancer patients and survivors: "There are good things and then there are bad things". Pediatric Blood and Cancer 2014; 61: S357.

36. Himelstein BP, Hilden JM, Boldt AM, et al. Pediatric palliative care. N Engl J Med 2004; 350: 1752-1762. 2004/04/23. DOI: 10.1056/NEJMra030334.

37. World Health Organisation. WHO Definition of Palliative Care, http://www.who.int/cancer/palliative/definition/en/ (2002, accessed March, 2019).

38. World Health Organisation. International Classification of Functioning, Disability and Health Geneva World Health Organisation Press 2001

39. Rubin HJ and Rubin IS. Qualitative Interviewing : The art of hearing data 3rd ed.: Thousand Oaks, CA Sage 2012.

40. Harding R, Selman L, Agupio G, et al. Validation of a core outcome measure for palliative care in Africa: the APCA African Palliative Outcome Scale. Health and Quality of Life Outcomes 2010; 8. DOI: 10.1186/1477-7525-8-10.

41. Clasberry E U. Culture Of Names In Africa: A Search for Cultural Identity. Xlibris, Corp, 2012

42. Woodgate RL and Degner LF. A substantive theory of Keeping the Spirit Alive: the Spirit Within children with cancer and their families. Journal of pediatric oncology nursing : official journal of the Association of Pediatric Oncology Nurses 2003; 20: 103-119. DOI: 10.1053/jpon.2003.75.

43. McSherry M, Kehoe K, Carroll JM, et al. Psychosocial and spiritual needs of children living with a life-limiting illness. Pediatric Clinics of North America 2007; 54: 609-629, ix-x. Review.

44. Bluebond-Langner M, DeCicco and Schwallie MN. Children's views of death. In: Goldman R, Hain R and Liben S (eds) Oxford Textbook of Palliative Care for Children. Oxford: Oxford University Press, 2012.

45. Forrester AB, Barton-Gooden A, Pitter C, et al. The lived experiences of adolescents with sickle cell disease in Kingston, Jamaica. Int J Qual Stud Health Well-being 2015; 10 : 28104. 2015/09/06. DOI: 10.3402/qhw.v10.28104.

46. Ljungman G, Gordh T, Sorensen S, et al. Pain in paediatric oncology: interviews with children, adolescents and their parents. Acta Paediatr 1999; 88: 623-630. Research Support, Non-U S Gov't.

47. Dame CS. The "Philosophy of terminal care," In: Saunders C (ed) The Management of malignant disease, . Arnold Publishers 1984, pp.232-241.

48. Reynolds BC, Windebank KP, Leonard RC, et al. A comparison of self-reported satisfaction between adolescents treated in a "teenage" unit with those treated in adult or paediatric units. Pediatr Blood Cancer 2005; 44: 259-263. 2004/10/30. DOI: 10.1002/pbc.20208. 49. Marshall S, Grinyer A and Limmer M. The 'lost tribe' reconsidered: Teenagers and young adults treated for cancer in adult settings in the UK. Eur J Oncol Nurs 2018; 33: 85-90. 2018/03/20. DOI: 10.1016/j.ejon.2018.02.001.

50. Matza LS, Patrick DL, Riley AW, et al. Pediatric patient-reported outcome instruments for research to support medical product labeling: report of the ISPOR PRO good research practices for the assessment of children and adolescents task force. Value Health 2013; 16 : 461-479.

51. Wallander JL, Schmitt M and Koot HM. Quality of life measurement in children and adolescents: Issues, instruments, and applications. Journal of Clinical Psychology 2001; 57: 571-585. DOI: 10.1002/jclp.1029. 